Journal of Animal and Veterinary Advances 11 (2): 241-244, 2012

ISSN: $1680-5593$

(C) Medwell Journals, 2012

\title{
Genetic Variation and Population Structure of the White Rhinoceros
}

\author{
Guanyu Hou, Hongpu Zeng, Dongjin Wang and Hanlin Zhou \\ Tropical Crops Genetic Resources Institute, CATAS, \\ 571737 Danzhou, Hainan, China
}

\begin{abstract}
As early as 3000 years ago, China has already had the records about rhinoceroses but they were extinct in the mid-19th century. In 2001, Sanya Long Hui Animal Breeding Co., Ltd. imported White Rhinoceros from South Africa. In order to investigate the genetic variation and genetic structure of the white rhinoceros, 64 individuals were detected with 41 microsatellites loci. The result indicated that 7 of the 41 microsatellites loci yielded positive polymorphic bands, the average observed homozygosity was 0.2009 , the homozygosity expected was 0.7400 , the average polymorphism information content was 0.692 and the average number of alleles was 5.4285. Based on these data, researchers suggested that more attention should be paid to the discovery of White Rhinoceros individuals with rare allelic genotypes and at the same time more breeding opportunities needed to be provided for these individuals to avoid the loss of rare alleles. Rhinoceros is highly endangered species and the data obtained in this research could provide information relevant to their conservation.
\end{abstract}

Key words: White rhinoceros, microsatellite, genetic variation, population structure, species, Africa

\section{INTRODUCTION}

About 3000 years ago, there were three kinds of wild rhinoceroses lived in the vast area of China: Sumatran rhinoceros (Dicerorhinoceross sumatrensis), Javan rhinoceros (Rhinoceros sondaicus) and Greater OneHorned rhinoceros (Rhinoceros unicornis). The northern distribution boundary was $>1800 \mathrm{~km}$ along Yellow river (Sun et al., 1998).

Rhinoceroses have suffered a decline in population numbers and become extinct in the mid 19th century (Lan, 1992; Zai-Fu, 2000). One reason is human population explosion has resulted in habitat destruction and encroachment. Perhaps, the main reason however, centers on widespread hunting for their horns and skins. Although, rhinoceros has been extinct in China, it can be reintroduced in recent environment ( $\mathrm{Zai}-\mathrm{Fu}, 2000)$. The white Rhinoceros (Ceratotherum simum) is a herbivorous grazer that belongs to the order of the perissodactyla and is the largest species of land mammal after the elephant. The Northern White Rhinoceros subspecies has been declared extinct in recent years although, some may survive. The total southern white rhinoceros population which fell to about 20 animals a century ago (Emslie and Brooks, 1999) were protected and have recovered to about 14,530 animals today. Sanya Long Hui Animal Breeding Co., Ltd. introduced the Southern subspecies from South Africa in 2001. Rhinoceroses are in captivity in Sanya, Hainan province and most of them are young but much stronger than those in the wild. Microsatellite DNA also known as Simple Sequence repeats is tandem repeats which consist of repeat units of 2-6 bp nucleotide sequence. It has many advantages such as a high polymorphism, easy detection and good reproducibility which is considered as the most ideal molecular marker for the study of population genetic variation (Powell et al., 1996; Russell et al., 1997).

It has also been widely used in the researches of endangered animal population and conservation genetics. Zhang et al. (2003) successfully identified the relationships of seven Siberian tigers descendants which had unclear father-son relationships by using 10 pairs of microsatellite primers. Shen et al. (2009) analyzed wild and captive panda populations by using 11 pairs of microsatellite primers and they found that captive panda population has experienced a genetic bottleneck. In order to understand the population genetics of the White Rhinoceros populations, the polymorphic microsatellite markers for the present state of endangerment are described.

\section{MATERIALS AND METHODS}

Sampling and DNA extraction: Total 64 blood samples were collected from rhinoceros in Sanya Long Hui Animal Breeding Co., Ltd. Genomic DNA was extracted from blood sample as the described in Molecular cloning; a laboratory manual, 3rd ed (Sambrook and Russell, 2001)

Corresponding Author: Guanyu Hou, Tropical Crops Genetic Resources Institute, CATAS, 571737 Danzhou, Hainan, China 
and detected by $0.8 \%$ agarose gel electrophoresis. The content of DNA was estimated by ultraviolet spectrophotometer and the genome DNA was diluted to $50 \mathrm{ng} \mu \mathrm{L}^{-1}$.

Primer design, PCR protocols: Primer pairs were designed for 27 loci using primer (Ver. 5.0), fourteen highly polymorphic primers from the black bicornis were chosen (Cunningham et al., 1999; Brown and Houlden, 1999). The PCR reactions were carried out in a total volume of $20 \mu \mathrm{L}$ solution containing $50 \mathrm{ng}$ template DNA, $1 \times$ buffer (Tris- $\mathrm{HCl} 100 \mathrm{mmol} \mathrm{L}^{-1}, \mathrm{pH} 8.3 ; \mathrm{KCl} 500 \mathrm{mmol}$ $\mathrm{L}^{-1}$ ), $0.25 \mu \mathrm{mol} \mathrm{L}{ }^{-1}$ primers, $2.0 \mathrm{mmol} \mathrm{L}^{-1} \mathrm{MgCl}_{2}$, $0.25 \mathrm{mmol} \mathrm{L}^{-1} \mathrm{dNTPs}$ and $0.5 \mathrm{U}$ Taq DNA polymerase (TaKaRa, Dalian, China). The reaction conditions of PCR were: $95^{\circ} \mathrm{C}$ for $5 \mathrm{~min}$ followed by 35 cycles of $94^{\circ} \mathrm{C}$ for $30 \mathrm{sec}$, appropriate $\mathrm{Tm}\left(49-64^{\circ} \mathrm{C}\right)$ for $30 \mathrm{sec}, 72^{\circ} \mathrm{C}$ for $30 \mathrm{sec}$ and a final extension step at $72^{\circ} \mathrm{C}$ for $10 \mathrm{~min}$. The PCR products were detected on a $2 \%$ agarose gel.

Capillary gel electrophoresis: After PCR amplification, the bench-type High performance DNA Analysis (HDA) GT12 system with QIAxcel DNA screening kit provided by eGene was used. The system was operated according to eGene's operation manual. Amplified DNA solution $(15 \mu \mathrm{L})$ was transferred to a $0.2 \mathrm{~mL}$ vial and was placed in the instrument sample tray.

The DNA samples were automatically injected into the capillary channel and subjected to electrophoresis by selecting the AM320.mtQ method from eGene's BioCalculator $^{\mathrm{TM}}$ software. The quantificaion of DNA fragmnents was based on the integrated peak area determined by eGene's BioCalculator software.

Statistical analysis: Observed homozygosity $\mathrm{H}_{\mathrm{O}}$, observed heterozygosity $\mathrm{H}_{\mathrm{E}}$, epected homozygosity $\mathrm{H}_{\mathrm{O}}$, expected heterozygosity $\mathrm{H}_{\mathrm{E}}$, observed number of alleles
$\mathrm{Na}$, effective number of alleles $\mathrm{Ne}$, Shannon index were calculated using the POPGENE software (Ver. 3.2) and PIC were calculated using the CERVUS software (Ver. 2.0).

\section{RESULTS AND DISCUSSION}

Results of polymorphisms: About 7 of the 41 microsatellites loci yielded positive polymorphic bands, 15 a monomorphic pattern and the primers for the remaining 19 loci yielded multiple amplification bands (Table 1). The PCR products of primer DB52 of the rhinoceros populations (Fig. 1). The genetic polymorphisms of the populations were detected by AM320 method suing BioCalculator ${ }^{\text {TM }}$ software (Fig. 2).

Characters in the population: The information of genetic diversity of the white rhinoceros populations were shown in Table 2 . The 7 polymorphic microsatellites loci tested in white rhinoceros population demonstrated high allelic variation with the number of alleles ranging from $4 \pm 8$ alleles per locus (Table 3 ).

All the PIC values were $>0.50$ which indicated the locus in the population had high-level heterozygosities. The researchers provided basic population genetic data for a set of microsatellite markers in White Rhinoceros which would be useful for population genetics studies.

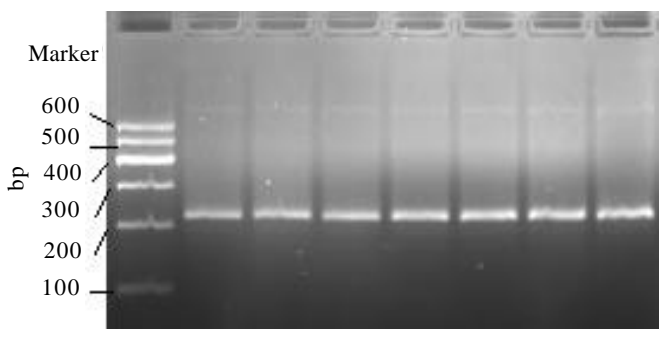

Fig. 1: The PCR products of primer DB52

Table 1: The information of microsatellite primers

\begin{tabular}{lll}
\hline SSR locus & Primer sequence $\left(5^{\prime}-3^{\prime}\right)$ & \\
BR4 & CCCCTAAATTCTAGGAACAC & CCAAAGACCACCAGTAATTC \\
BR6 & TCATTTCTTTGTTCCCCATAGCAC & AGCAATATCCACGATATGTGAAGG \\
DB14 & CTTCTGGATTATACTGCTCACC & TCTCCCACAACATTCTCATCC \\
DB23 & CCTCAGCAATAAGGGGAGGATTAGC & GTTGATTCTCTGCCCCTGAGTTTGGG \\
DB30 & GCGACTATGACATACAACTATCTAC & GGTCAAGGATTATTCTGACTAGC \\
DB42 & CCTGTTAGTGTAACTTCTATGCTCCC & CATGGATGTTAGCTCAGGGCTGATC \\
DB52 & CATGTGAAATGGACCGTCAGG & ATTTCTGGGAAGGGGCAGG \\
\hline
\end{tabular}

Table 2: The allele frequencies of the Rhinoceros populations

\begin{tabular}{|c|c|c|c|c|c|c|c|c|}
\hline SSR locus & 1 & 2 & 3 & 4 & 5 & 6 & 7 & 8 \\
\hline$\overline{\mathrm{BR} 4}$ & 0.0938 & 0.1406 & 0.4375 & 0.2188 & 0.0391 & 0.0703 & - & - \\
\hline BR6 & 0.0391 & 0.0859 & 0.2188 & 0.2031 & 0.0313 & 0.1719 & 0.0469 & 0.2031 \\
\hline DB14 & 0.2031 & 0.2188 & 0.2031 & 0.2031 & 0.1719 & - & - & - \\
\hline DB23 & 0.0703 & 0.1719 & 0.3125 & 0.2031 & 0.2031 & 0.0391 & - & - \\
\hline DB30 & 0.1250 & 0.1094 & 0.4297 & 0.3359 & - & - & - & - \\
\hline DB42 & 0.5469 & 0.2344 & 0.1719 & 0.0469 & - & - & - & - \\
\hline DB52 & 0.3672 & 0.3281 & 0.1797 & 0.0625 & 0.0625 & - & - & - \\
\hline
\end{tabular}


Table 3: The information of genetic diversity of the Rhinoceros populations

\begin{tabular}{|c|c|c|c|c|c|c|c|c|}
\hline SSR locus & Obs $\mathrm{H}_{0}$ & $\mathrm{Obs} \mathrm{H}_{\mathrm{E}}$ & $\operatorname{Exp} \mathrm{H}_{0}$ & $\operatorname{Exp} H_{E}$ & PIC & $\mathrm{Na}$ & $\mathrm{Ne}$ & $\mathrm{I}$ \\
\hline BR4 & 0.9062 & 0.0938 & 0.2741 & 0.7259 & 0.690 & 6.0000 & 3.5742 & 1.4928 \\
\hline BR6 & 0.6250 & 0.3750 & 0.1655 & 0.8345 & 0.805 & 8.0000 & 5.8141 & 1.8720 \\
\hline DB14 & 0.9844 & 0.0156 & 0.1955 & 0.8045 & 0.767 & 5.0000 & 4.9558 & 1.6048 \\
\hline DB23 & 0.7656 & 0.2344 & 0.2084 & 0.7916 & 0.751 & 6.0000 & 4.6598 & 1.6301 \\
\hline DB30 & 0.4688 & 0.5312 & 0.3198 & 0.6802 & 0.616 & 4.0000 & 3.0762 & 1.2314 \\
\hline DB42 & 1.0000 & 0.0000 & 0.3809 & 0.6191 & 0.559 & 4.0000 & 2.5924 & 1.1162 \\
\hline DB52 & 0.8438 & 0.1562 & 0.2760 & 0.7240 & 0.668 & 5.0000 & 3.5509 & 1.3951 \\
\hline Mean & 0.7991 & 0.2009 & 0.2600 & 0.7400 & 0.692 & 5.4285 & 4.0319 & 1.4774 \\
\hline
\end{tabular}

Obs_ $\mathrm{H}_{\mathrm{O}}$ : Observed Homozygosity; Obs_ $\mathrm{H}_{\mathrm{E}}$ Observed Heterozygosity; Exp_ $\mathrm{H}_{\mathrm{O}}$ : Homozygosity Expected; Exp_H⿷ $\mathrm{H}_{\mathrm{E}}$ : Heterozygosity Expected; PIC: Polymorphism Information Content; Na: Number of Alleles; Ne: Effective number of alleles; I: Shannon Index

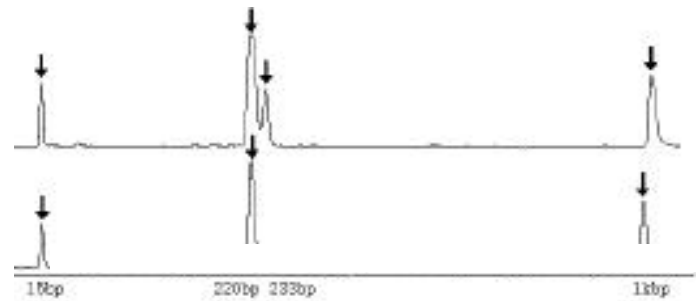

Fig. 2: The heterozygosis and homozygous of primer DB52

However, the gene diversity of the Rhinoceros population analyzed in this study was more limited and lower than that reported for other herbivores using microsatellite DNA markers as well.

Heterozygosity reflects the population genetic variation in loci which is an optimal parameter to measure population genetic variation (Nei et al., 1975). In this study, the mean value of observed homozygosity (0.2009) was lower than that of heterozygosity expected $(0.7400)$. The main cause of this result might be the intense artificial selection, inbreeding and small number of founders for foreign breeds. It might also be due to the insufficient sample number and the statistical error. Harley et al. (2005) found the observed heterozygosity and heterozygosity expected of 3 Black Rhinoceros subspecies (D.b. Minor, D.b. bicornis, D.b. michaeli) were $0.436,0.523,0.731$ and $0.459,0.505$ and 0.675 , respectively by using microsatellite data from nine loci and 121 black rhinoceros individuals.

The heterozygosity expected $(0.7400)$ of White Rhinoceros was higher than that of Black Rhinoceros (0.459-0.675) which indicated that the genetic variation level of White Rhinoceros was higher than that of Black Rhinoceros. Loci are high polymorphic when PIC $>0.5$ (Vanhala et al., 1998). In this study, all loci used were high polymorphic and with the highest value 0.805 (BR6) which showed that the Rhinoceros population had greater genetic variation and their polymorphism information content was higher. The reason might be due to the Rhinoceros population used in this study were taken from the wild Rhinoceros in South Africa.

\section{CONCLUSION}

In this study more homogeneous distribution of alleles in the population, the closer values between effective number of alleles and number of alleles. In this study, DB14 loci Na and Ne were the closest. However, BR4 loci $\mathrm{Na}$ and $\mathrm{Ne}$ was the farthest with an average number of alleles to be higher than the average effective number of alleles.

It is noteworthy that the average number of alleles of White Rhinoceros was only 5.4285 and the distribution frequency of partial population alleles was very low. Some of the Rhinoceros in captivity could not effectively breed due to space constraints in captivity during their breeding period which could lead to the loss of some population alleles and the decrease of population genetic diversity.

\section{RECOMMENDATIONS}

Therefore, during the breeding period of White Rhinoceros in addition to avoid the inbreeding and increase the population individual number how to maintain the genetic diversity is an important problem. In order to prevent the loss of rare alleles, researchers suggested that more attention should be paid to the discovery of individuals with rare allelic genotypes and at the same time, more breeding opportunities needed to be provided for these individuals to make the distribution of population rare alleles more uniform and to avoid the loss of rare alleles.

\section{ACKNOWLEDGEMENT}

Researchers thank Sanya Long Hui Animal Breeding Co., Ltd. to provid blood samples. Many thanks to Dr. Dai $\mathrm{Yu}$ who studies in the research center for eco-environmental sciences, Chinese academy of sciences for his assistance of literature consulting and suggestions of thesis writing. 


\section{REFERENCES}

Brown, S.M. and B.A. Houlden, 1999. Isolation and characterization of microsatellite markers in the black rhinoceros (Diceros bicornis). Mol. Ecol., 8: 1559-1561.

Cunningham, J., E.H. Harley and C. O'Ryan, 1999. Isolation and characterisation of microsatellite loci in black thinoceros (Diceros bicornis). Electrophoresis, 20: $1778-1780$.

Emslie, R.H. and M. Brooks, 1999. African Rhinoceros: Status Survey and Conservation Action Plan. IUCN/SSC African Rhinoceros Specialist Group, Gland, Switzerland, Cambridge, UK, ISBN: 9782831705026, Pages: 92.

Harley, E.H., I. Baumgarten, J. Cunningham and C. O'ryan, 2005. Genetic variation and population structure in remnant populations of black rhinoceros, Diceros bicornis, in Africa. Mol. Ecol., 14: 2981-2990.

Lan, Y., 1992. Extinguishment of wild thinoceros unicornis in Southwest China. J. Sichuan Teachers Coll. (Nat. Sci.), 13: 92-95.

Nei, M., T. Maruyama and R. Chakraborty, 1975. The bottleneck effect and genetic variability in populations. Evolution, 29: 1-10.

Powell, W., M. Morgante, C. Andre, M. Hanafey, J. Vogel, S. Tingey and A. Rafalski, 1996. The comparis on of RFLP, RAPD, AFLP and SSR (Microsatellite) markers for germplasm analysis. Mol. Breed., 2: 225-238.
Russell, J.R., J.D. Fuller, M. Macaulay, B.G. Hatz, A. Jahoor, W. Powell and R. Waugh, 1997. Direct comparison of levels of genetic variation among barley accessions detected by RFLPs, AFLPs, SSRs and RAPDs. Theor. Applied Genet., 95: 714-722.

Sambrook, J. and D.W. Russell, 2001. Molecular Cloning: A Laboratory Manual. 3rd Edn., Cold Spring Harbor Laboratory Press, New York, ISBN-13: 9780879695774, Pages: 99.

Shen, F., Z. Zhang, W. He, B. Yue and A. Zhang et al., 2009. Microsatellite variability reveals the necessity for genetic input from wild giant pandas (Ailuropoda melanoleuca) into the captive population. Mol. Ecol., 18: 1061-1070.

Sun, G., K. Jin and Z.T. Wang, 1998. A spatial-temporal model of rhinoceros extinction in China. J. For. Res., 9: 129-130.

Vanhala, T., M. Tuiskula-Haavisto, K. Elo, J. Vilkki and A. Maki-Tanila, 1998. Evaluation of genetic distances between eight chicken lines using microsatellite marker. Poult. Sci., 77: 783-790.

Zai-Fu, X., 2000. The effects of paying tribute to the imperial court in the history on rhinoceros extinction and elephant's endangerment in Southern Yunnan. Chin. Biodivers., 8: 112-119.

Zhang, Y.G., D.Q. Li, L.Q. Rao, Q.M. Xiao and D. Liu, 2003. Identification of polymorphic microsatellite DNA loci and paternity testing of Amur tigers. Curr. Zool., 49: 118-123. 